\title{
Secondary Metabolites as Stimulants and Antifeedants of Salix integra for the Leaf Beetle Plagiodera versicolora
}

\author{
Amir Reza Jassbi* \\ Laboratory of Ecological Chemistry, Division of Applied Bioscience, Graduate School of \\ Agriculture, Hokkaido University, Kita-ku, Sapporo 060-8589, Japan. Fax: +81-11-706-4281. \\ Email.arjassbi@hotmail.com \\ * Corresponding Address: Department of Phytochemistry, Medicinal Plants Research \\ Institute, Shahid Beheshti University, Evin, Tehran, Iran. Fax: +98-21-2418679. \\ Email.a-jassbi@cc.sbu.ac.ir \\ Z. Naturforsch. 58c, 573-579 (2003); received January 30, 2003 \\ Plagiodera versicolora, a willow beetle living on S. sachalinensis, is found on S. integra \\ during early June in Hokkaido Island, Japan. This insect selects several species of willows \\ (Salix), including S. integra as host plant in Honshu Island of Japan. To determine the reasons \\ for the limited distribution of this beetle on the willows of Hokkaido, the feeding preference \\ of the insect to leaves of S. integra and its constituents was performed. Feeding-bioassay \\ guided fractionation of an $80 \%$ aqueous acetone extract of fresh leaves of Salix integra to \\ Plagiodera versicolora resulted in isolation of feeding stimulant and antifeeding constituents. \\ Chlorogenic acid (1) and 3,5-dicaffeoyl quinic acid (2) were identified as antifeedants and \\ 1,2-di[(9Z,12Z,15Z)-octadeca-9,12,15-trienoyl]-3- $\beta$-D-galactopyranosyl-sn-glycerol (MGDG, \\ 3 ) as feeding stimulants. The feeding test was performed by an agar disk method. The treated \\ agar disks contained sucrose and test sample in different doses. The antifeeding activities of \\ $\mathbf{1}$ and $\mathbf{2}$ and stimulant activity of $\mathbf{3}$ may be one of the reasons for the limited presence of $P$. \\ versicolora on S. integra in Hokkaido.
}

Key words: Salix integra, Plagiodera versicolora, Chrysomelidae

\section{Introduction}

Plagiodera versicolora Laicharting is a willow beetle found on Salix sachalinensis, in Ishikari near Sapporo, Hokkaido, Japan. The body of the adult beetle is about $3-4 \mathrm{~mm}$ long with a coloring of shiny steel blue. Ishihara et al. (1999) investigated the life cycle of Plagiodera versicolora. Two generations were reported for this insect in Hokkaido, while multivoltine cycle (they complete 56 life cycle per year) was reported in Honshu Island of Japan (Kimoto and Takizawa, 1994). Ishihara et al. (1999) described several reasons for this finding, "why the willow beetles select $S$. sachalinensis as their host plant", as follows: (1) it may be caused by high quality of $S$. sachalinensis as food. (2) The bivoltine cycle in the field may be maintained by a high growth rate on $S$. sachalinensis. (3) Predation pressure on S. integra may cause that $P$. versicolora avoid oviposition on this plant.

Studies on the life cycle of $P$. versicolora in Hokkaido showed that besides the continuous presence of the insect on $S$. sachalinensis as its host plant, during early June the number of adult insects increased on $S$. integra for a few days and again decreased at the end of the season.

The feeding behavior of $P$. versicolora on different species of Salix on Honshu Island suggested salicin, populin and luteolin-7-glucoside as feeding stimulants (Matsuda and Matsuo, 1985). Even chlorogenic acid, which has antifeeding activity for some willow beetles, was found in the leaves of $S$. integra to be a feeding stimulant for $P$. versicolora (Matsuda and Senbo, 1986).

The quality and chemical constituents of leaves of different Salix species as food for chrysomelidae leaf beetles were studied thoroughly (Ikonen, 2001). The palatability of leaves of some salicaceous plants (Populus and Salix species) for leaf beetles of chrysomelidae family, including $P$. versicolora showed that the younger leaves are consumed more (Ikonen, 2002). Secondary metabolites such as phenolic glycosides including salicin and related compounds, chlorogenic acid and condensed tannins exist in higher concentration in younger leaves. Despite the defensive role of the secondary metabolites, the beetles generally prefer 
the younger leaves to the older ones (Ikonen, 2002). The analysis of the leaves of several willows showed high contents of nitrogen in the younger leaves of the plants and hence more nutrients for the beetles (Ikonen, 2002). The effect of phenolic secondary compounds including salicin and related glucosides and chlorogenic acid on feeding preference of leaf beetle Agelastica alni was investigated (Ikonen et al., 2002). Agelastica alni is an oligophagous leaf beetle utilizes both alders and willows. Alnus incana is its preferred host plant. In addition $S$. phylicifolia and $S$. caprea were consumed moderately but this beetle rejected other willows ( $S$. pentandra and S. myrsinifolia). The presence of chlorogenic acid and a salicylate-type phenolic glucoside, salicin, inhibited the feeding of A. alni in the bioassay with pure phenolic compounds. High chlorogenic acid and salicylate content of the rejected willows leaves explain their poor palatability. In contrast a feeding stimulant in the leaves of the host plant, $A$. incana that overcomes the deterrent activities of the above-mentioned phenolic compounds has been proposed (Ikonen et al., 2002).

My objective was to determine the possible chemical compounds responsible for the reduced tendency of $P$. versicolora to select S. integra in Hokkaido as its host plant. Also the question was addressed, why the beetles live on S. integra in the field in the beginning of the season while its host plant is $S$. sachalinensis.

\section{Material and Methods}

\section{General procedure}

${ }^{1} \mathrm{H}$ and ${ }^{13} \mathrm{C}$ NMR spectra (broad band and DEPT expts.) were measured on a JEOL, JNM-EX270 instrument. MS spectra were recorded on a JEOL JMS-SX102A spectrometer. Optical rotations were determined on a JASCO DIP-370 digital polarimeter. Analytical TLC experiments were performed on Merck silica gel $60 \mathrm{~F}_{254}$, DIOL F 254 HPTLC and RP-18 $\mathrm{WF}_{254}$ HPTLC pre-coated glass plates. HPLC was performed on a Hitachi L-6000 with an L-4200H UV-vis detector and a Hitachi D-2500 Chromato-integrator, Tokyo, Japan, using a semipreparative RP-18 (Prep-ODS Inertsil $6.0 \times$ 250 mm, GL Science, Tokyo, Japan) column.

\section{Leaf beetles}

Plagiodera versicolora were caught at the adult stage on S. sachalinensis and reared on leaves of the same plant. The rearing and all the feeding tests were performed in a growing chamber, NK system controller Biotron NC 220 (Nippon Medical and Chemical Co. LTD., Osaka, Japan) at $21-23{ }^{\circ} \mathrm{C}$, relative humidity of $65 \%$ and $16 \mathrm{~h}$ light and $8 \mathrm{~h}$ dark.

\section{Chemicals}

Chlorogenic acid (1) was purchased from Aldrich Chemical Company. It was also purified from the leaves of S. integra. 3,5-Dicaffeoyl quinic acid (2)

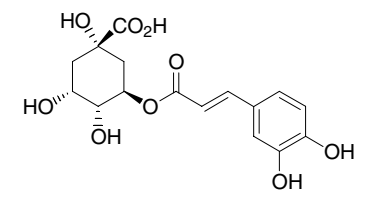

Chlorogenic acid (1)

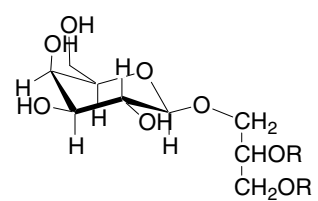

$\mathrm{R}=\mathrm{CO}\left(\mathrm{CH}_{2}\right){ }_{7} \mathrm{CH}=\mathrm{CHCH}_{2} \mathrm{CH}=\mathrm{CHCH}_{2} \mathrm{CH}=\mathrm{CHCH}_{2} \mathrm{CH}_{3}$

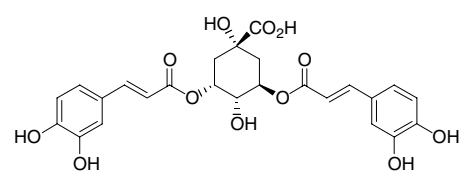

3,5-Dicaffeoyl quinic acid (2)

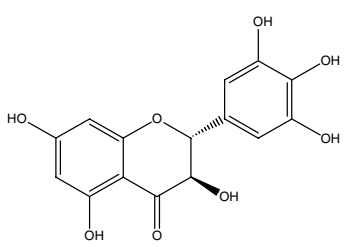

Ampelopsin (4)
Fig. 1. Antifeeding and feeding stimulant constituents from $S$. integra $(\mathbf{1 - 3})$ and $S$. sachalinensis (4). 
and 1,2-di[(9Z,12Z,15Z)-octadeca-9,12,15-trienoyl]3- $\beta$-D-galactopyranosyl-sn-glycerol (MGDG, 3) were extracted and purified from the leaves of $S$. integra. Ampelopsin (4) was purified previously from S. sachalinensis (Fig. 1) (Matsumoto and Tahara, 2001).

\section{Agar disk bioassay}

The bioassay procedure was based on counting the agar disk area consumed by the adult beetles (Matsumoto, 2000). The agar mixture was made by mixing of $3.25 \mathrm{~g}$ sucrose, $0.75 \mathrm{~g}$ agar, and $25 \mathrm{ml}$ de-ionized water and heating to make a clear solution. The hot liquefied agar was poured into the bigger lid of a Petri dish and immediately the smaller lid was used to press the agar solution. The thickness of the agar layer was adjusted by putting three pieces of $\Phi 0.3 \mathrm{~mm}$ lead pencil as a triangle between two lids of the Petri dish before adding the agar solution. After a few min the agar layer was solidified and it was cut to $1 \mathrm{~cm}$ circles. Two agar disks $(\Phi 1 \mathrm{~cm})$ were put on inner side of bigger lid of an $\Phi 6 \mathrm{~cm}$ Petri dish and an $\Phi 55 \mathrm{~mm}$ wet filter paper was put on the inner side of the smaller lid of the dish to maintain the moisture in the vessel. One of the agar disks was treated with a $10-\mu$ solution of the test compound in acetone or $80 \%$ acetone in water and another with only solvent as the control. Five 1 to 7 -day old adult beetles were released inside the dish. The beetles were starved between 20 to $24 \mathrm{~h}$ before test. The area of the consumed agar disk was calculated by counting the square units of a haemacytometer, which was placed under the agar disks as the background. The percentage of the feeding index was calculated by the following equation: \% Feeding index $=(\mathrm{T}-\mathrm{C} / \mathrm{T}+\mathrm{C}) \times 100$. Where $\mathrm{T}$ is the number of the consumed squares of the treated agar disk and $\mathrm{C}$ is that for the control disk. The positive and negative sign of the feeding index indicates the feeding stimulant and antifeeding activities, respectively.

\section{Isolation of the chemical constituents of S. integra}

The leaves (515 g fresh), of $S$. integra, collected from Atsubetsu in July 2001 in Sapporo, were extracted with $80 \%$ aqueous acetone. The extraction was done twice for two weeks. The aqueous acetone extract of the leaves was con- centrated in reduced pressure to give $c a .110 \mathrm{~g}$ of residue, which was partitioned between water and ethyl acetate. The ethyl acetate fraction was divided into acidic (42 g) and neutral fractions ( $15 \mathrm{~g})$ by partitioning between ethyl acetate and $5 \% \mathrm{NaHCO}_{3}$ followed by neutralization of the latter layer by $2 \mathrm{~N} \mathrm{HCl}$ solution and extraction with ethyl acetate.

\section{Purification of the water-soluble part of the aqueous acetone extract of $S$. integra}

The water layer fraction of the aqueous acetone extract (33.0 g out of $51.5 \mathrm{~g}$ residue) was subjected to Sephadex LH20 (200 g) column chromatography using aqueous methanol (from $70 \%$ to $100 \%$ methanol v/v). The fractions 2 and 3 (70\% methanol, $8.8 \mathrm{~g}$ ) contained mostly two compounds which were separated on a LiChroprep ${ }^{\circledR} \mathrm{NH}_{2}$ (40$63 \mu \mathrm{m}$ ) column using $\mathrm{CH}_{3} \mathrm{CN}$ and increasing the polarity up to $30 \%$ aqueous $\mathrm{CH}_{3} \mathrm{CN}$. They were identified as fructose and sucrose (50:50) by comparison of FAB-MS and ${ }^{13} \mathrm{C}$ NMR spectral data and Co-TLC with authentic samples on silica gel thin layer plates in $\mathrm{CHCl}_{3}: \mathrm{CH}_{3} \mathrm{OH}: \mathrm{H}_{2} \mathrm{O}$ : $\mathrm{HOAc}$ $(5: 3: 1: 1 \mathrm{v} / \mathrm{v} / \mathrm{v} / \mathrm{v})$, and in the same system replacing $\mathrm{CHCl}_{3}$ by EtOAc. The rest of the fraction was predominant in chlorogenic acid (1), which was identified by Co-TLC on silica gel thin layer plates (eluent: $\mathrm{CHCl}_{3}: \mathrm{CH}_{3} \mathrm{OH}: \mathrm{H}_{2} \mathrm{O}: \mathrm{HOAc}$, 5:3:1:1 $\mathrm{v} / \mathrm{v} / \mathrm{v} / \mathrm{v}$ ) in comparison to an authentic sample. FAB mass spectrum, ${ }^{1} \mathrm{H}$ and ${ }^{13} \mathrm{C}$ NMR spectral data confirmed the structure of $\mathbf{1}$.

Identification of the constituents of the acidic layer of the aqueous acetone fraction

The HPLC chromatogram of the acidic fraction, recorded using an RP HPLC using MeOH:H2O: HOAc (40:60:2 v/v/v) showed two main compounds $\mathbf{1}$ and 2 at $3.92 \mathrm{~min}$ and $7.92 \mathrm{~min}$, respectively. The UV detector was set at $326 \mathrm{~nm}$ and the flow rate was $1.5 \mathrm{ml} / \mathrm{min}$. The major compounds were identified as chlorogenic acid (1) and 3,5-dicaffeoyl quinic acid (2) by comparison of FD-MS, ${ }^{1} \mathrm{H}$ and ${ }^{13} \mathrm{C}$ NMR and CD spectral data with those reported in the literature (Chuda et al., 1996; Basnet et al., 1996). 
Constituents of the aqueous methanol extract of the leaves of S. integra

The fresh leaves $(650 \mathrm{~g})$ of $S$. integra collected in October 2000, once extracted with ethyl acetate were soaked in $70 \%$ methanol in water for one week. Evaporation of the aqueous solvent under vacuum resulted in a brown syrup, which was then dissolved in ethyl acetate $(13 \mathrm{~g})$ and the residue was dissolved in water $(48 \mathrm{~g})$. The ethyl acetate soluble part of the extract was subjected to silica gel CC using chloroform with increasing amounts of methanol $(0-100 \%)$. The fractions checked by TLC, revealed that the less polar fractions were identical with those in the hexane soluble part of the first ethyl acetate extract. The latter fractions 11-13 (3.45 g) contained mostly the glycolipids. The major compound was purified by repeated flash silica CC using chloroform: ethyl acetate: acetone: methanol $(3: 1: 1: 0.2 \mathrm{v} / \mathrm{v} / \mathrm{v} / \mathrm{v})$. The structure was determined using HRFAB-MS, ${ }^{1} \mathrm{H}$ and ${ }^{13} \mathrm{C}$ NMR spectroscopy as 1,2 -di [ $(9 Z, 12 Z, 15 Z)$-octadeca-9,12,15-trienoyl]-3- $\beta$-D-galactopyranosyl-snglycerol (3, MGDG) (Adebodun et al., 1992; Coddington et al., 1981).

Spectral data and physical constants for compounds 1-3 isolated from Salix integra

Chlorogenic acid (1): FAB- MS: 353 (M-1) ${ }^{-}$. $[\alpha]_{\mathrm{D}}^{25}-16.6^{\circ}\left(c, 0.6\right.$ in $\left.\mathrm{CH}_{3} \mathrm{OH}\right) .{ }^{1} \mathrm{H}$ NMR $\left(\mathrm{CD}_{3} \mathrm{OD}\right.$, $270 \mathrm{M} \mathrm{Hz}): \delta 7.54(d, J=15.9 \mathrm{~Hz}), 7.04(s), 6.93(d$, $J=7.7 \mathrm{~Hz}), 6.77(d, J=7.7 \mathrm{~Hz}), 6.26(d, J=$ $15.9 \mathrm{~Hz}), 5.34(\mathrm{~m}), 4.16(b r s), 3.72(\mathrm{brd}, J=7.5 \mathrm{~Hz})$, $2.0-2.20(m, 4 \mathrm{H}) .{ }^{13} \mathrm{C}$ NMR $\left(\mathrm{CD}_{3} \mathrm{OD}, 67.5 \mathrm{~m} \mathrm{~Hz}\right)$ : $\delta$ 175.2, 168.7, 149.5, 147.0, 146.7, 127.7, 122.9, 116.4, 115.3, 115.2, 73.7, 72.1, 71.7, 39.1, 38.3.

3,5-dicaffeoyl quinic acid (2): FAB- MS: 515 $(\mathrm{M}-1)^{-} \cdot[\alpha]_{\mathrm{D}}^{25}-81.4^{\circ}\left(c, 0.7\right.$ in $\left.\mathrm{CH}_{3} \mathrm{OH}\right) .{ }^{1} \mathrm{H}$ NMR $\left(\mathrm{CD}_{3} \mathrm{OD}, 270 \mathrm{~m} \mathrm{~Hz}\right): \delta 7.52(d, J=15.9 \mathrm{~Hz}), 7.48(d$, $J=15.9 \mathrm{~Hz}), 6.96(s, 2 \mathrm{H}), 6.85(d, J=8.3 \mathrm{~Hz}), 6.68$ $(d, J=8.3 \mathrm{~Hz}), 6.24(d, J=15.9 \mathrm{~Hz}), 6.16(d, J=$ $15.9 \mathrm{~Hz}), 5.30(m, 2 \mathrm{H}), 3.89(d d, J=3.3,7.5 \mathrm{~Hz})$, $2.0-2.30(m, 4 \mathrm{H}) .{ }^{13} \mathrm{C}$ NMR $\left(\mathrm{CD}_{3} \mathrm{OD}, 67.5 \mathrm{~m} \mathrm{~Hz}\right)$ : $\delta$ 177.4, 168.8, 168.4, 149.3, 149.2, 147.2, 147.0, 146.4, $127.7,127.5,123.0,122.9,116.4,115.4,115.2,115.1$, $114.9,74.7,72.5,71.8,70.7,37.7,35.9$.

1,2-di[(9Z,12Z,15Z)octadec-9,12,15-trienoyl]-3- $\beta$ D-galactopyranosyl-sn-glycerol] (MGDG， 3): FD MS: $797(\mathrm{M}+\mathrm{Na})^{+}, 775(\mathrm{M}+\mathrm{H})^{+}, 612(\mathrm{M}-162)^{+}$. $[\alpha]_{\mathrm{D}}^{25}+2.3^{\circ}\left(c, 6\right.$ in $\left.\mathrm{CHCl}_{3}\right) \cdot{ }^{1} \mathrm{H}$ NMR $\left(\mathrm{CDCl}_{3}\right.$,
270 м Hz): $5.39(m, 12 \mathrm{H}), 4.40(d d, J=3.2,11.9 \mathrm{~Hz})$, $4.28(d, J=11.9 \mathrm{~Hz}), 4.20(d d, J=6.9,11.9 \mathrm{~Hz}), 4.01$ $(b r d), 3.95(d d, J=5.9,12.2 \mathrm{~Hz}), 3.88(d, J=5.7 \mathrm{~Hz}$, $2 \mathrm{H}), 3.74(d d, J=6.2,11.3 \mathrm{~Hz}), 3.67(d, J=9.5 \mathrm{~Hz})$, $3.60(m, 2 \mathrm{H}), 2.80(m, 8 \mathrm{H}), 2.31(m, 4 \mathrm{H}), 2.10(m$, $8 \mathrm{H}), 1.60(m, 4 \mathrm{H}), 1.30(m, 16 \mathrm{H}), 0.97(t, J=7.5 \mathrm{~Hz}$, $6 \mathrm{H}) .{ }^{13} \mathrm{C} \mathrm{NMR}\left(\mathrm{CDCl}_{3}, 67.5 \mathrm{~m} \mathrm{~Hz}\right): 173.5,173.1$, 131.7, 129.9, 128.1, 127.9, 127.5, 126.8, 103.9, 73.4, $70.9,70.0,68.7,67.8,62.8,61.2,34.2,34.0,29.7,29.6$, $29.2,29.1,29.1,29.0,27.1,25.6,25.5,24.8,20.5,14.3$.

\section{Bioassay-guided fractionation of the $80 \%$} acetone extract of the leaves of S. integra

The willow beetles were subjected to agar disk feeding tests using different fractions of the aqueous acetone extract of $S$. integra. The weight of the crude aqueous acetone extract from each $\Phi 1 \mathrm{~cm}$ disk of the leaves $(10-15 \mathrm{mg}$ ) was about $1-2 \mathrm{mg}$. The above-mentioned amount (1-2 mg) of the extract was charged on each agar disk $(\Phi 1 \mathrm{~cm})$. The aqueous acetone extract of the leaves of S. integra collected in August 2001 (220 mg) was partitioned between water/ether and water/hexane separately and each of the ethereal $(40 \mathrm{mg})$ and hexane (46 mg) fractions was used for the feeding tests. The bioassay showed antifeeding for the water $(-30 \%)$ and ether $(-26.5 \%)$ extract while the feeding of the beetles were stimulated $(7.4 \%)$ by charging the hexane fractions on the agar disks. In order to find the active constituents, the hexane fraction $(88 \mathrm{mg}$ ) was subjected to a silica gel flash column chromatography using hexane, with increasing polarity up to pure ethyl acetate. The fractions containing compound $\mathbf{3}(5 \mathrm{mg})$ were the stimulant active ones. The major constituents of ether fraction and water layer were compounds 2 and $\mathbf{3}$, by separation on an RP 18 reverse phase TLC using $1 \%$ acetic acid in $40 \%$ solution of methanol in water as the mobile phase. The amount of 2 and $\mathbf{3}$ separated from $26 \mathrm{mg}$ of the $80 \%$ aqueous acetone extract was 6 and $3 \mathrm{mg}$, respectively. The pure compounds, 1, 2, 3 and 4 were used in different doses in the agar disk bioassay to evaluate their effect on the feeding behavior of $P$. versicolora.

After performance of the feeding tests the results were analyzed statistically. The average, standard deviation and standard errors of the means were calculated for each experiment with at least 

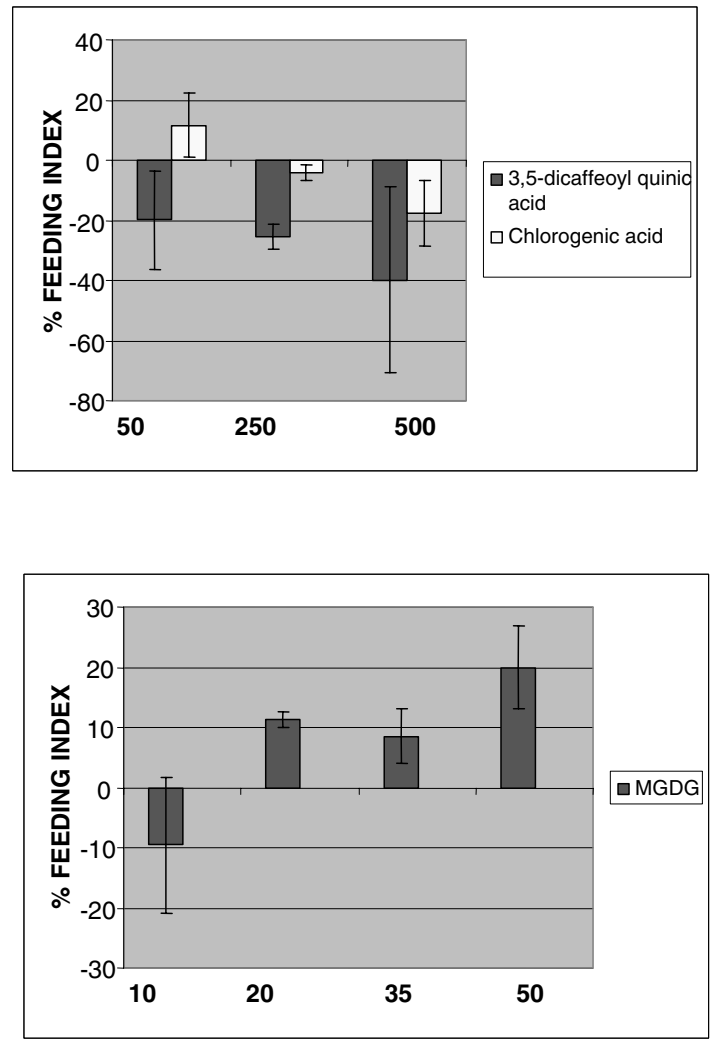

Fig. 2. The results of feeding tests with different doses $(\mu \mathrm{g})$ of compounds $\mathbf{1}$ and $\mathbf{2}$ (upper part) and $\mathbf{3}$ (lower part) charged on each agar disk. The vertical bars shows standard errors of the mean values, obtained from 6 replicates $(n=6)$. Dose: mean value of feeding index (standard error of the mean value) for $\mathbf{1}$ [50 $\mu \mathrm{g}: 11.5$ (10.6), $250 \mu \mathrm{g}:-4.2(2.6), 500 \mu \mathrm{g}:-17.8(10.9)], 2$ [50 $\mu \mathrm{g}:$ - 19.8 (16.4), $250 \mu \mathrm{g}:-25.5$ (4.1), $500 \mu \mathrm{g}:-39.8$ (30.8)] and 3 [10 $\mu \mathrm{g}:-9.6(11.2), 20 \mu \mathrm{g}: 11.3$ (1.4), $35 \mu \mathrm{g}: 8.5$ (4.5), $50 \mu \mathrm{g}: 20.0(6.9)]$.

six replicates for each dose (Lowry, 1998-2003). The analytical results of the tests are presented in Figs. 2 and 3.

\section{Results and Discussion}

The results of the tests showed antifeeding activity for chlorogenic acid (1) and 3,5-dicaffeoyl quinic acid (2) (Fig. 2) in the range of 50-500 $\mu \mathrm{g}$ per agar disk. The higher activity of compound $\mathbf{2}$ in comparison to $\mathbf{1}$ may be due to the incorporation of another caffeoyl moiety in position 5 of 2 . To the best of my knowledge, compound $\mathbf{2}$ is reported as an antifeeding agent to $P$. versicolora isolated for the first time from $S$. integra. Accord-

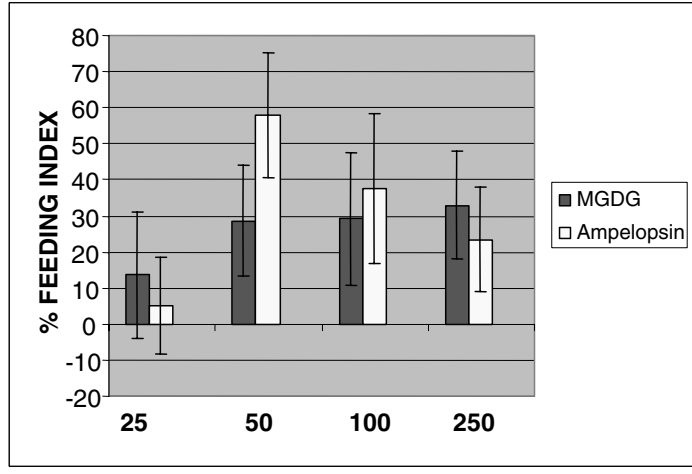

Fig. 3. Feeding stimulant activity of MGDG (3): dose: mean value of feeding index (standard error of the mean value) [25 $\mu \mathrm{g}: 13.6$ (17.5), $50 \mu \mathrm{g}: 28.7$ (15.3), $100 \mu \mathrm{g}: 29.3$ (18.4), $250 \mu \mathrm{g}: 33.0$ (15.1)] isolated from $S$. integra and ampelopsin (4) [25 $\mu \mathrm{g}: 5.3$ (13.4), $50 \mu \mathrm{g}: 57.9$ (17.3), $100 \mu \mathrm{g}: 37.5$ (20.9), $250 \mu \mathrm{g}: 23.5$ (14.4)] from S. sachalinensis at different doses $(\mu \mathrm{g})$. The vertical bars shows standard errors of the mean values, obtained from 6 replicates $(n=6)$.

ing to Fig. 2, compounds $\mathbf{1}$ and $\mathbf{2}$ showed antifeeding activities above $50 \mu \mathrm{g}$ per agar disk. The deterrent doses were consistence with the concentration of these substances in the leaf of the plant based on the same area as for the agar disk.

The feeding stimulant activity of ampelopsin (4), the major flavonoid of $S$. sachalinensis (Matsumoto and Tahara, 2001; Matsumoto, 2000) to $P$. versicolora, is compared to that of MGDG (3) from S. integra (Fig. 3). Ampelopsin has been reported as an abundant flavonoid in S. phylicifolia leaves but with no strong antiherbivore activity against $A$. alni (Ikonen, 2001). The presence of a feeding stimulant (3) in the leaves of $S$. integra may overcome the antifeeding effect of other compounds ( $\mathbf{1}$ and $\mathbf{2}$ ) so that the beetles consume the leaves (Ikonen et al., 2002). This can be a reason why the beetles still consume the leaves of $S$. integra. When the leaves of $S$. integra and $S$. sachalinensis were exposed to willow beetles, although the growing diet for the beetles was the leaves of $S$. sachalinensis, the beetles ate the young leaves of both willows equally. They did not consume the older (harder) leaves. This might be due to high quality or existence of more nutrient constituents in the younger leaves (Ikonen, 2002).

$S$. sachalinensis is the major host plant of $P$. versicolora in Sapporo area while in the Honshu Island several species of willow were found to be 
the host plants for $P$. versicolora (Matsuda and Matsuo, 1985; Matsuda and Senbo, 1986). This might be due to the presence of some stimulants such as salicin and its derivative populin or the flavonoid glucoside, luteolin-7-glucoside in the leaves of different Salix species. The feeding stimulant activity of chlorogenic acid in Salix integra of Honshu Island, to P. versicolora might be the result of the adaptation of the insects to use this compound in Honshu Island (Matsuda and Senbo, 1986).

Two chemical races for $S$. sachalinensis have been reported so far (Mizuno et al., 1991). However we could not detect significant differences in the chemical constituents of the leaves of different clones of $S$. integra collected from various places of Sapporo (Shinkawa, Atsubetsu and Ishikari). Chlorogenic acid is determined as the major active constituent in both Sapporo and Sendai specimens of S. integra (Matsuda and Senbo, 1986). Some secondary metabolites such as salicin and related phenolic glycosides have both feeding deterrent activity for some non-adapted insects and feeding stimulant activity for some adapted insects (Matsuda and Senbo, 1986; Ikonen, 2002). The present paper reports chlorogenic acid as a compound, which has two opposite effects on the feeding beha- vior of $P$. versicolora in different climates. Besides the defensive role of chlorogenic acid to phytophagous insects, it shows a positive or negative effect on growth of different insects (Todd et al., 1971; Chawla et al., 1974; Matsuda and Senbo, 1986). I observed faster growth and less mortality for the willow beetles using the leaves of $S$. sachalinensis (prominent in ampelopsin) instead of S. integra (prominent in chlorogenic acid) as the rearing diet.

The presence of two kinds of stimulants and antifeedants in the leaves of $S$. integra may lead us to assume that the presence and absence of $P$. versicolora on $S$. integra might be due to a balance of these compounds in different seasons. To confirm this phenomenon the leaves of $S$. integra should be quantitatively analyzed for compounds 1, 2 and $\mathbf{3}$ from May to September.

\section{Acknowledgments}

I am grateful to Prof. Dr. Satoshi Tahara for his kind support of this project and his advice and encouragement during my postdoctoral course. I am thankful to the "Japan Society for the Promotion of Science" for granting the post-doctoral fellowship. My thanks are expressed to Dr. Eri Fukushi and Mr. Kenji Watanabe for their skilful measuring the NMR and MS spectra. 
Adebodun F., Chung J., Montez B., Oldfield E., and Shan X. (1992), Spectroscopic studies of lipids and biological membranes: carbon-13 and proton magicangle sample-spinning nuclear magnetic resonance study of glycolipid-water systems. Biochemistry 31, 4502-4509.

Basnet P., Matsushige K., Hase K., Kadota S., and Namba T. (1996), Four di-O-caffeoyl quinic acid derivatives from propolis. Potent hepatoprotective activity in experimental liver injury models. Biol. Pharm. Bull. 19, 1479-1484.

Chawla S. S., Perron J. M., and Cloutier M. (1974), Effects of different growth factors on the potato aphid, Macrosiphum euphorbiae (Aphididae: Homoptera), fed on artificial diet. Can. Ent. 106, 273-280.

Chuda Y., Ono H., Ohnishi-Kameyama M., Nagata T., and Tsushida T. (1996), Structural identification of two antioxidant quinic acid derivatives from garland (Chrysanthemum coronarium L.) J. Agric. Food Chem. 44, 2037-2039.

Coddington J. M., Johns S. R., Leslie D. R., Willing R. I., and Bishop D. G. (1981), ${ }^{13}$ C nuclear magnetic resonance studies of the composition and fluidity of several chloroplast monogalactosyldiacylglycerols. Biochim. Biophys. Acta 663, 653-660.

Ikonen A. (2002), Preferences of six leaf beetle species among qualitatively different leaf age classes of three salicaceous host species. Chemoecology 12, 23-28.

Ikonen A. (2001), Leaf beetle feeding pattern on and variable plant quality in betulaceous and salicaceous Hosts. PhD Dissertation in Biology No. 10, University of Joensuu, Finland.

Ikonen A., Tahvanainen J., and Roininen H. (2002), Phenolic secondary compounds as determinants of the host plant preferences of the leaf beetle, Agelastica alni. Chemoecology 12, 125-131.
Ishihara M., Hayashi T., and Ohgushi T. (1999), Life cycle of the willow beetle, Plagiodera versicolora (Coleptera: Chrysomelidae) in Ishikari (Hokkaido, Japan). Entemol. Sci. 3, 57-60.

Kimoto S., and Takizawa H. (1994), Leaf beetles (Chrysomelidae) of Japan. Tokai University Press, Tokyo. (In Japanese)

Lowry R., VassarStats: (1998-2003) Web Site for Statistical Computation Vassar College Poughkeepsie, NY, USA (http://faculty.vassar.edu/lowry/VassarStats.html).

Matsumoto T. (2000), Feeding characters of Plagiodera versicolora and chemical constituents of Salix species. M. Sc. Dissertation, Graduate School of Agriculture, Hokkaido University, Sapporo, Japan. (In Japanese)

Matsumoto T., and Tahara S. (2001), Ampelopsin, a major antifungal constituent from Salix sachalinensis, and its methyl ethers. Nippon Nôgeikagaku Kaishi 75, 659-667. (In Japanese)

Matsuda K., and Matsuo H. (1985), A flavonoid, luteolin-7-glucoside, as well as salicin and populin, stimulating the feeding of leaf beetles attacking salicaceous plants. Appl. Ent. Zool. 20, 305-313.

Matsuda K., and Senbo S. (1986), Chlorogenic acid as a feeding deterrent for the Salicaceae-feeding leaf beetle, Lochmaeae capreae cibrata (Coleoptera: Chrysomelidae) and other species of leaf beetles. Appl. Ent. Zool. 21, 411-416.

Mizuno M., Kato M., Iinuma M., Tanaka T., Kimura A., Ohashi H., Sakai H., and Kajita T. (1991), Further study on two chemical races of Salix sachalinensis FR. Schmidt. Chem. Pharm. Bull. 39, 803-804.

Todd G. W., Getchum A., and Cress D. C. (1971), Resistance in barley to greenbug, Schizaphys graminum L. Toxicity of the phenolic and related compounds and related substances. Ann. Entomol. Soc. Am. 64, $718-722$. 